\title{
Editorial: Welcome to the Humanistic Management Journal
}

\author{
Michael Pirson ${ }^{1}$
}

Published online: 29 July 2016

C) Springer International Publishing 2016

\section{Introduction}

Welcome to the inaugural edition of the Humanistic Management Journal, the journal of the Humanistic Management Network. Founded in 2005, the Humanistic Management Network (HMN), has at its core the transformation towards a life-conducive economic system through better management practices.

As the Humanistic Management Manifesto states:

We believe that market economies hold a substantial potential for human development in general. To promote life-conducive market activities, we want to complement the quantitative metrics, which hitherto define managerial and economic success with qualitative evaluation criteria that focus on the human dignity and well-being of every woman and every man.

In business as well as in society, respect for human dignity demands respect for human freedom. Collective decision-making, in corporations just as in governments, should hence be based on free and equal deliberation, participation or representation of all affected parties. Concerns of legitimacy must, in economics like in politics, precede questions of expediency.

The Humanistic Management Network defends human dignity in face of its vulnerability. The dignity of the human being lies in its capacity to define autonomously the purpose of its existence. Since human autonomy realizes itself through social cooperation, economic relations and business activities can either foster or obstruct human life and well-being. Against the widespread objectification of human subjects into human resources, against the common instrumentalization of human beings into human capital and a mere means for profit, we uphold humanity as the ultimate end and principle of all economic activity.

Michael Pirson

pirson@fordham.edu

1 Fordham University, Bronx, NY, USA 
The Humanistic Management Network brings academics from all disciplines together and promotes collaboration with thought and action leaders in practice, public policy and media. Since the foundation the HMN fostered collaborations across the globe through book projects, conferences, workshops and partnerships with a number of other institutions ${ }^{1}$ to promote a lifeconducive economy. Our main contribution rests in the specification and promotion of a humanistic organizing paradigm that allows for application in business but also in other organizations including NGO's, universities, hospitals and government agencies.

\section{Why Would We Need Yet Another Journal?}

The world is experiencing a multitude of crises that are, if not caused, facilitated by organizing practices in the widest sense. We, the editors, felt the need for an academic journal dedicated to the broader challenges and potential solutions provided by management and organizing theory. Whether we do or do not combat climate change, whether and how we counter the threat of global terrorism, if and how we address social inequality are all questions of management. The current debate on solutions, is often dominated by an 'economistic' paradigm wherein pricing in an externality seems to be the only conceivable solution to any issue with the logic of exchange being the exclusive lens.

While we do not dispute the power and ability of markets to create desired outcomes, we also maintain that more is required to create a life-conducive economy than mere exchange,namely "dignity." As the German philosopher Kant famously put it:

In the kingdom of ends everything has either a price or a dignity. What has a price can be replaced by something else as its equivalent; what on the other hand is above all price and therefore admits of no equivalent has a dignity.

In a nutshell, the idea behind humanistic management is to bring the notion of dignity (back) to management theory and practice. We argue that the function of organizing is not only wealth creation but well-being creation in a way and form expressive and supportive of human dignity. We clearly acknowledge the importance of wealth as a factor in well-being and human flourishing but underline that a good and dignified life requires more than financial wealth. This perspective, still underrepresented in business scholarship, requires more attention. This is what we created this journal for.

\section{Basic Pillars of Humanistic Management and the HMJ}

Humanistic Management rests on the foundations of humanism. Humanism entails a comprehensive view of human beings and their dignity with all their potentials. These potentials include rationality, freedom, rational learning (professional and moral development), openness to friendly relations with other people and nature, moral discernment and a sense of transcendence. Human beings therefore need to be considered as a certain absolute, endowed with dignity and called to flourish in their humanity not a mere instrument for economic purposes

${ }^{1}$ Such as the Global Ethic Institute, Fordham University, the Academy of Management, the OECD 
only. For humanistic management we then consider human beings as the origin, center, and end of economic activity as fundamental principle.

The basic pillars of humanistic management rest on the notion of dignity, well-being and flourishing. We aim to specify what these pillars mean throughout the first years of the Humanistic Management Journal beginning with this issue, yet do not want to over-specify at this point.

\section{The Ambition and Direction of the HMJ}

The ambition of the Humanistic Management Journal is to span academic disciplines and bring together thought leaders from civil society, business practice and public policy to engage in a conversation on how organizing practices can facilitate a 'life-conducive economic system."

The Humanistic Management Journal will have a wide scope in its contents. It is open to humanistic approaches from the humanities including philosophical, theological and religious studies as well as the natural and social sciences. Both conceptual and empirical manuscripts will be welcomed.

As we state on our webpage:

The humanistic management journal focuses on the protection of human dignity and the promotion of human well-being within the context of organizations. It connects disparate fields including business ethics, sustainability and management studies via a humanistic research paradigm. It is

- A venue for multiple academic disciplines and inter/trans-disciplinary work that focuses on understanding and enhancing the protection of human dignity and the promotion of wellbeing in organizing processes.

- A venue for researchers, practitioners, and policy makers interested in a life-conducive economic system.

- Follows the trend in humanistic management toward social entrepreneurship and cooperative capitalism

As social entrepreneurship, for-benefit businesses, and conscious, regenerative, and cooperative capitalism gain visibility, this is a forum for researchers, practitioners, and policy makers interested in a life-conducive economic system for which humanistic management is the underpinning.

The editorial team invites you all to contribute to this conversation. We are committed to facilitating your contributions with dignity and respect.

Helping us in our work will be a number of outstanding thought leaders from academia, practice and public policy who joined our Editorial Board:

Romina Boarini, Senior Economist, OECD, Paris, France

Jane Dutton, Professor of Organizational Behavior, University of Michigan, USA

Ed Freeman, Professor of Strategic Management, University of Virginia, USA

Consuelo Garcia de la Torre, Professor EGADE Business School, Tec de Monterrey,

Mexico

Mary Gentile, Professor University of Virginia, Founder Giving Voice to Values 
Anil Gupta, Professor, IIM Ahmedabad, Founder, Honey Bee Network, India

Andre Habisch, Professor of Business Ethics, KU Eichstaett, Germany

Ellen Langer, Professor of Psychology, Harvard University, USA

Donna Hicks, Associate, Weatherhead Center, Harvard University

Chris Laszlo, Professor of Organizational Behavior, Case Western Reserve University

L. Hunter Lovins, Professor of Sustainable Business, Bard College

Henry Mintzberg, Professor of Strategic Management, McGill University, Canada

Roger Martin, Dean Emeritus Rotman School of Business, Canada

Jonas Haertle, United Nations Global Compact (PRME),

JC Spender, Research Professor, Kozminski University, Poland

Shann Turnbull, Principal, Institute for Self-Governance, Sydney, Australia

Anne Tsui, Professor Emerita Arizona State University, and Former AOM President

Sandra Waddock, Professor of Strategy, Boston College, USA

Our editorial board will advise us on topics, areas and fora to look out for. We are very grateful for their commitment to the HMJ.

If you are interested in supporting the mission and work of the HMJ please feel free to be in touch with the editors. We also invite all of you interested in collaborating to consider submitting your work and even serve as reviewers.

Our first issue reflects the above ambition of crossing disciplines and sectors but is only a starting point.

The first two articles are written by our Associate Editors who provide foundational philosophical and historical context. Claus Dierksmeier provides an in-depth perspective on What is "humanistic" in humanistic management. Based on relevant conceptions of freedom Dierksmeier argues that humanistic management distinguishes itself based on the unconditional prescription of dignity and the creation of conditions for well-being. He outlines conceptual challenges to the humanistic perspective by the deep ecology movement as well as by anti-universalist postmodernists. He outlines some counter arguments and proposes humanistic management as a procedure (procedurial humanism).

Domenec Mele traces the historical development of humanistic management thinking beginning in the early $20^{\text {th }}$ century He also provides an overview of the various meanings of humanistic management that have developed. To make sense of the various uses Mele suggests understanding Humanism and its background more. He therefore develops five distinctive elements of humanism including wholeness, comprehensive knowledge, human dignity, development and the common good. He then suggests that humanism has influenced management thought and practice as an 'Ethos.' He further develops a catalogue of practices that reflect such a humanistic ethos in management.

The third article by Sandra Waddock, Galligan Chair of Strategy and Professor at Boston College, reflects the basic humanistic ethos and showcases how it can be applied in the area of management education. For her article:" Developing Humanistic Leadership Education" she draws on extensive interviews with 28 eminent, humanistic management scholars. She suggests that rather than reform the MBA programs that have received so much criticism, we should develop leadership programs that are wisdom based and can focus on "healing." In her suggestions she draws on ancient wisdom of shamanism to underscore how good education can lead to the creation of common good.

After the three introductory articles, we present a suite of articles that showcase a critical element of the Humanistic Management Journal: The platform for engagement with 
humanistic management actors from civil society, practice, pedagogy and public policy (The Humanistic Management Forum). These articles are meant to be impulses to strengthen our collective search for better organizing practices.

Leading off is prominent Environmental Sustainability pioneer and Executive Member of the Club of Rome, L. Hunter Lovins. She suggests we need a better story if we want to change the paradigm. She outlines the largest global problems we are facing. She also suggests that solutions for all of the major challenges exist, yet need to be scaled up. The biggest problem for scale remains a mindset shift that allows change on a global level. She proposes a procedure on how to develop such a strategy learning from the Mont Pelerin Society and the ensuing Powell Memorandum that created a pathway to the currently dominant "economistic" narrative.

In a follow-up article Sandra Waddock suggests a pathway to creating large system change based on foundational memes that support a new narrative. She explains how memes are the base element of cultural narratives and why some memes "stick" in various cultural contexts or not. She outlines the practice of meme shaping and identifies how Members of the Mont Pelerin Society have successfully shaped the neoliberal narrative. Waddock concludes with a list of new memes that can serve as the foundation of a new 'humanistic' narrative.

In a separate piece, one of the leading experts in the field of conflict resolution, Donna Hicks of Harvard University shares her dignity-related work in the corporate context. Donna Hicks outlines her dignity model with which she has successfully mediated conflicts in Colombia, Northern Ireland and many other places. When she was approached by a large American Airline she was taken by surprise initially only to discover how similar conflicts and dignity violations in the business context were. In her article she chronicles her experiences and outlines a couple of interventions designed to restore and protect dignity. Ultimately she concludes, the leadership of the airline was too stuck in the economistic narrative to resolve the conflict. Her article closes with a number of questions for reflection and an invitation to further engage in the exploration of how the meme of dignity can be helpful to better organizing practices.

Mary Gentile, a pioneer in value-based management pedagogy now based at the University of Virginia, is presenting a short impulse piece on how her award winning "Giving Voice To Values" (GVV) pedagogy might benefit from being connected to "Listening to Values" pedagogy. She outlines the core elements of GVV and then explores what more we need to do to hear the values being voiced within organizations. This is a novel quest, one that would benefit from co-creation and learning. She therefore ends her piece with some questions to facilitate that development.

To round out our humanistic management forum articles, we are happy to provide a voice from public policy. Martine Durand, Chief Statistician and Director of the OECD Statistics Directorate, and Romina Boarini, Senior Economist and Head of Measuring Well-Being and Progress Section at the OECD are explaining the background of a major shift at the OECD to measure progress more in line with Well-being than GDP or GNP. She presents an overview of the measurement details at the country level and also proposes to develop such measures for the firm level.

To provide space for short impulses and further reflections including book reviews we present another section: Humanistic Management Impulses

Within this section Anne Tsui former President of the Academy of Management shares her thoughts on the future of the Academy and how opening up the governance structure to integrate other voices (like those from practice and policy) could help make the work more 
rewarding and impactful. Jonathan Keir of the Global Ethic Institute (WeltEthos Institut) ${ }^{2}$ in Tuebingen Germany reflects on the role of the Global Ethic Project initiated by renowned Catholic Theologian Hans Kueng and how it can inform Humanistic Management research, practice and policy. Rea Raus of Tallinn University reviews 'Creative Social Change" a book by Kathryn Goldman Schuyler of Alliant International University. The edited volume builds on interviews with five eminent social scientists, Robert Quinn, Otto Scharmer, Edgar Schein, Peter Senge, and Margaret Wheatly, and presents contributions from a number of thought leaders in academia, practice and policy.

\section{Invitation to Contribute}

We hope that with the first issue you can get a sense of the breadth and depth of the Humanistic Management perspective. We also invite you to consider contributing your own work in this area. As we stated before, the Humanistic Management Journal spans disparate fields including business ethics, environmental sustainability, social responsibility and management studies, in a humanistic research paradigm. It is a venue for thought leaders from academia, practice and public policy

- interested in a life-conducive economic system

- embracing an Aristotelian conception of organizing/management aiming at "eudaimonia" also reflected in Amartya Sen and Martha Nussbaum's work.

- following the trend in humanistic management toward social entrepreneurship and cooperative capitalism

- viewing the planetary boundaries as driver of innovation for authentic and sustainable human flourishing

- considering the possibility of a Global ethos based on universal values (e.g. Hans Kuengs Global Ethic)

- working in the areas of management including but not limited to governance, strategy, flourishing, happiness, social innovation, empowerment, common good creation etc.

It would be wonderful if you considered a contribution along the above lines.

\section{Our Editorial Mission}

In our roles as editors we will be focusing on the facilitation of an ongoing discourse with our intellectual partners from across the sectors. We see our main role in the next years to stimulate and foster increasingly robust debates with consequences for organizing theory. We will rely on established authors that have worked in the field for a long time yet increasingly hope to give voice to emerging new scholars. We also wish this journal to go a pathway that very few other journals have traveled: we see it as an active engagement platform for those that consider themselves thought leaders be they currently active in academia or outside. Particularly important to a robust, relevant, rigorous and impactful conversation seems to us the inclusion of voices from civil society, business practice, public policy and possibly the media at large.

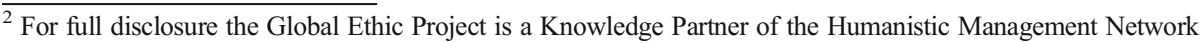


We will do our best to provide "impulse pieces" from various audiences for further discussion. These pieces may vary in length, provide one or several key ideas and often end with further questions for discussion. As such we hope to stimulate a true conversation and deeper reflection.

Of course the dynamics of the field, i.e. the pressure to establish a journal with academic impact as measured by traditional impact factors loom large. We will focus on developing rigorous scholarly content and feature a significant portion of those more traditional pieces. These pieces however and hopefully will increasingly showcase interdisciplinary character in that management research can actively draw on the wide range of natural and social sciences as well as the rich treasure trove that are the humanities. That deliberate broadening of disciplines should not distract from the focal point of the research and arguments presented in the journal: to increase understanding of organizing practices that protect human dignity and promote wellbeing.

We hope you enjoy our inaugural issue!

Michael Pirson

Claus Dierksmeier

Domenec Mele 